\title{
Etnomusicologia e estudos musicais: uma contribuição ao estudo acadêmico do jazz
}

\author{
Ethnomusicology and musical studies: \\ a contribution to the academic study \\ of the jazz
}

Acácio Tadeu de C. Piedade

Este trabalho se compõe de duas partes. Primeiramente, trata-se de uma revisão bibliográfica de alguns estudos musicais do campo da Etnomusicologia e ligados à Sociologia, Psicologia e Semiologia da música. 0 caráter geral é de síntese crítica, e o objetivo é apresentar algumas perspectivas abertas por estes estudos. $\mathrm{Na}$ segunda parte, partindo de uma experiência pessoal, se tentar descrever algumas características de um gênero musical específico - no caso, o jazz - que apontam para seu aspecto normativo e convencional, que é compartilhado por músicos e ouvintes; pretendese aludir à base sócio-cultural destas convenções, bem como ao código, que propicia o entendimento e aceitação de uma performance de jazz e determina o sucesso pela audiência. 0 campo musical aqui delimitado é, assim, passível de uma leitura semiótica. 0 conjunto deste texto, portanto, significa uma contribuição aos Estudos Musicais em geral, mais especificamente à Etnomusicologia, vindo a somar-se na recente perspectiva de abordagens antropológicas da música popular e do jazz. 


\section{Etnomusicologia}

Etnomusicologia é uma das três tradições musicológicas do Ocidente, juntamente com a Musicologia Histórica e a Sociologia da Música (Menezes Bastos, 1978:63). Outros campos de Estudos Musicais, como a Psicologia da Música e a Estética Musical, fazem parte deste "corpus scientiarum musicarum" (ver Menezes Bastos,1994). A Musicologia não nasce no campo epistêmico das Ciências Humanas, e sim no mundo da música do século XVIII, como um estudo que objetivava construir "partituras crítico-interpretativas" da música do passado, como é o caso do período do Barroco Musical (1600-1750). A origem da Musicologia Comparada, futura Etnomusicologia, está ligada à formação do Berlins Phonogramm Archiv e a figuras como Erich M. Von Hornbstel e Carl Stumpf, que constituem os pesquisadores mais célebres daquilo que se convencionou chamar de "Escola de Berlim" (Christensen, 1991). Os trabalhos e teorias produzidos neste "momento psicológico" da futura Etnomusicologia envolvem investigações acerca das sensações em relação aos sons, das propriedades dos sons, da natureza dos intervalos e escalas, da noção de consonância e outros temas (ver Shneider,1991). 0 conhecimento gerado por estes estudos, que trabalhavam com dados sobre as sociedades ditas "primitivas", eram marcados por idéias evolucionistas, e muitos dos conceitos neles implicados hoje se tornaram obsoletos. No entanto, estas obras portavam um impulso de alta relevância científica que contaminou a nascente "Musicologia Comparada". Um exemplo disto é a obra Tonpsychologie, onde Stumpf desenvolveu uma teoria da sensação do som e dos efeitos que a música causa nos ouvintes, 
teoria que forneceu uma base conceitual profícua, como a noção de "distância" (Stumpf,1883). Esta fundamentação foi essencial para várias obras posteriores, como a de Hornbostel e Abraham, que elaboram uma teoria dos constituintes do som, Helligkeit, Tonigkeit, Lautheit e Klangfarbe (Abraham e Hornbostel,1925; ver Schneider, op.cit.). Estas experiências, medições e generalizações, apesar de estarem ultrapassadas, basearam-se epistemologicamente na teoria de Stumpf, cuja base filosófica é ainda hoje de alto interesse, sendo apoiada na fenomenologia e na Denkpsychologie, relacionando-se ainda com a teoria da Gestalt e, mais recentemente, com a Psicologia Cognitiva.

De fato, o que na verdade florescia com o Arquivo de Berlim era o que se pode chamar de uma "Psico-Musicologia" (Menezes Bastos,1990) na qual a música e o comportamento humano eram investigados não como universos separados e meramente comunicantes, e sim apontando para um fenômeno integral. Esta visão da música será deixada de lado no período subseqüente, que será marcado pela cisão teórica entre o mundo da música e o da cultura (ver abaixo), vindo a se aproximar somente das perspectivas mais recentes, que tomam a música como som estruturado, como "fato social total" (Feld,1984;Menezes Bastos,1990). Portanto, neste gesto primeiro da Escola de Berlim de Musicologia Comparada está, "dissolvido pela postura etnológica ilustrativo-exemplificadora, (...) o ponto de chegada paralisado, congelado como pedra d'água, de todo um diligente saber sobre a música como linguagem semanticamente plena" (pp.496). 
Pode-se dizer que a segunda guerra mundial liquidou, ainda que temporariamente, o "espírito de Berlim": exilada da Alemanha, a nascente Etnomusicologia naturaliza-se norteamericana e, neste país, se institucionaliza e se desenvolve academicamente. Nos Estados Unidos do pós-guerra e nos anos 50 havia, no campo disciplinar da Etnomusicologia, duas abordagens preponderantes: a primeira, marcada pelos estudos da Musicologia Histórica, e cujos apóstolos eram Hood e Kolinski, reduzia a música ao seu plano da expressão; a outra, cujo nome mais importante é o de Lomax, reagia à esta redução e acabava negligenciando a parte sonora da música, fundando-se numa semântica destituída de substância.

Em meio a este embate teórico, surge a obra de Merriam (1964), que procura criar bases para resolver o caráter dilemático que está estampado em cada uma destas abordagens: Merriam mostra o dilema congênito que se estabelece na disciplina, o chamado "dilema etnomusicológico", segundo o qual a música se constitui de dois planos distintos, o dos sons e 0 dos comportamentos. A Etnomusicologia teria nascido no meio destes pólos, o primeiro sendo objeto da Musicologia e, o segundo, da Antropologia. Esta disciplina, portanto, seria marcada por um abismo, que Merriam tenta transpor. Criado na tradição culturalista de Boas, influenciado por Kroeber e aluno de Herskovits, Merriam buscou esclarecer o campo epistemológico da Etnomusicologia e posicionoua como uma ponte entre as Ciências Humanas e as Humanidades (op.cit:25), e proferiu a célebre definição da disciplina como "o estudo da música na cultura" (op.cit:6, o grifo é meu). 
Não tão citado como teórico, Nettl (1964) é uma figura-chave no cenário da Etnomusicologia. Suas concepções não se encaixam propriamente em nenhuma das duas principais correntes da Etnomusicologia norteamericana: a corrente de acento preponderantemente musicológico de Kolinsky e Mantle Hood e a linha mais antropológica que tem Merriam como principal referência. Em seu estudo de 1964, aporta tanto aspectos essencialmente musicológicos, como um apego às análises e descrições de composições musicais, quanto discussões mais antropológicas, como sobre papel da música na cultura, sobre a questão da mudança e sobre conceitos como musical area. A Etnomusicologia é vista como "a disciplina que busca o conhecimento da música do mundo, com ênfase na música que está fora da cultura do pesquisador, a partir de um ponto de vista descritivo e comparativo" (pp.11), o que implica para a Etnomusicologia norte-americana ter como objeto central três tipos de música: a das culturas não-letradas, a das avançadas sociedades orientais e a folclórica ocidental.

Outra importante lanterna teórica, Blacking (1973) tenta romper com a dicotomia música/cultura (o "dilema congênito" da disciplina) mediante a realização de uma descrição etnomusicológica que seja compatível com os modelos nativos, no caso, os Venda e outros grupos africanos. Blacking destaca a importância do contexto cultural onde os termos dos estilos musicais se fundam: "seus termos são aqueles da sociedade e da cultura, e dos corpos dos seres humanos que os escutam, criam e executam" (p.25). Duas outras importantes conquistas de Blacking foram estudar tanto a questão da habilidade musical dos nativos sem 
critérios etnocêntricos quanto os processos de geração (composição) musical. Assim, ele ressalta a importância da questão do creative listening para lembrar o papel competente e criativo dos ouvintes e a necessidade do etnomusicólogo de descobrir os princípios que geram a composição musical. Para ele, é um perigo analisar a música somente com base no som, ou no que chama sonic order, pois há ainda o nível das combinações motívicas e o do sentido (para aonde aponta a canção). Ao tratar da questão do sentido, no entanto, Blacking termina reduzindo tudo ao social: como se a música fosse somente reflexo e resposta a forças da dimensão social da realidade, ele se refere a ela como "uma expressão metafórica de sentimentos associados com o modo como a sociedade realmente" (p.104); deste modo, na busca de encontrar resposta à questão "quão musical é o homem?", Blacking se apropria de uma lente essencialmente sociológica, embora na formulação da questão ressalte os aspectos mais antropológicos, referentes à natureza do homem e da cultura. Mas isto constitui apenas uma característica de seu trabalho, que representa não apenas uma herança de Merriam, mas uma importante tentativa superação da formulação emblemática da "música na cultura".

Autores mais recentes já superaram a dicotomia música/cultura, mostrando como há uma interação tão forte nestes campos que a música não pode ser compreendida independentemente da cultura e da sociedade na qual ela é produzida. Um exemplo é o estudo de Feld sobre a música dos Kaluli da Nova Guiné (1982). Os nexos entre música e mito são os pontos centrais deste estudo, que começa com uma análise estrutural do mito do pássaro Muni, 
no qual há uma transformação metafórica de homens em pássaros e a transferência de certas palavras Kaluli para o canto dos pássaros. Feld chega à constatação de que a metáfora da canção do pássaro constrói a música Kaluli, as melodias, por sua vez, apontando para o canto dos pássaros.

Feld investiga o ethos desta sociedade nova-guinense através do estudo do som como sistema de símbolos relacionados à idéia essencial de tornar-se um pássaro. Epistemologicamente situado entre o sentimento e os pássaros, o som tem uma relação metonímica com o primeiro e metafórica com o segundo: trata-se de uma interface entre cultura e natura. Além dos conjuntos de canções e da taxonomia ornitológica, a investigação inclui o choro ritual e as formas poéticas que, relacionados ao mito do pássaro Muni, levam ao entendimento da vida nesta sociedade e à idéia de que as expressões sonoras são materializações de sentimentos profundos dos Kaluli.

Apoiada na antropologia interpretativa e na teoria da performance, Roseman estuda o imbricamento entre música e medicina nos Temiar, habitantes da floresta tropical da Malásia (1991). Roseman se utiliza do aporte teórico da Etnomusicologia e da etnomedicina para dar conta de explicar seu objeto: a confluência da música e da medicina, que "nos convida a reexaminar a pragmática da estética, a investigar como certas formas de som, movimento, cor e odor se tornam repositórios de poder cosmológico e social" (pp.11). A constatação, de que os compositores Temiar são médiuns, e as canções são elo entre eles se os espíritos. Como os curandeiros, no entanto, 
recebem as canções de espíritos-guia durante os sonhos, a análise de narrativas de sonho se tornam para Roseman objetos de estudo. As performances cerimoniais de cura, envolvendo também o transe, são estudados pela autora em sua perseguição às teorias indígenas que ali subjazem e à maneira como significações emocionais e poderes curadores são ali invocados.

A originalidade da obra de Keil sobre a música dos Kiv da Nigéria (1979) começa pelo fato dele não ter realizado um trabalho de campo convencional, devido sucessivos golpes militares e matanças neste país. 0 autor teve que realizar suas pesquisas sofrendo as mazelas dessa situação, mas as reflexões que a partir delas surgiram enriquecem 0 texto. A abordagem inclui um roteiro também original, partindo das palavras e fantasias para a vida e a ação. Assim, Keil trabalha inicialmente com verbos e palavras Tiv ligados à criação musical e ao canto e fenômenos associados, aumentando aos poucos o escopo lexical de sua investigação terminológica. A pertinência destes estudos se explica porque eles "abrem as portas para a comunicação e nos mergulham nos mundos problemáticos da tradução, da semântica, da definição de conceitos, da estética" (pp.28). Parte depois para algumas estórias e mitos Tiv, destacando como as canções se associam a eles. Passa então para a esfera da vida num estudo biográfico de compositores Tiv; a seguir, a partir de observações, apresenta descrições de características gerais das canções e esboça uma teoria das expressões Tiv, apesar de ter em mãos poucos dados etnográficos. 0 autor assumidamente mistura descrições idealistas e explicações materialistas, num conflito que, 
segundo ele, reflete aquele entre os compositores Tiv e sua sociedade.

Deve-se mencionar a importância da recente pesquisa etnomusicológica na Amazônia. Nesta área, os sistemas musicais nativos imbricam-se nos domínios dos saberes, havendo portanto necessidade da compreensão da música para além da ordem sônica, tomando-a como um "sistema significante de relevância estratégica para a construção do real" (Menezes Bastos e Lagrou,1995:2). A música amazônica lança desafios ao próprio conceito de música, enriquecendo portanto todo o campo da Musicologia, Teoria Musical e Filosofia da Música. Diversos autores têm que criar novos conceitos, como por exemplo "Arte Verbal", que dá conta das transformações que ocorrem no domínio da fala e que fazem com que esta seja considerada um fenômeno musical, os limites entre música e fala sendo aqui portanto tênues (Seeger,1987;Hill,1983). A música ocupa um lugar central tanto na cosmologia das culturas amazônicas -como elemento significante presente desde o tempo mítico-, quanto nas curas xamânicas -como instrumento de comunicação com o mundo sobrenatural-, nos rituais -como meio de recriação do tempo mítico-, e em diversas funções cotidianas e comunicativas (ver Menezes Bastos,1978,1990; Piedade,1997a; Basso, 1985).

No campo dos estudos acadêmicos da música popular, um dos pensadores mais salientes é Shepherd (1991) que, com viés sociológico e apoiado nos Estudos Culturais, analisa os processos, texturas, estruturas e significações musicais na música "clássica" e popular, entendendo a música como "texto social". Shepherd (1987) aborda a temática das 
relações de gênero e suas correlações com elementos musicais, afirmando que a hegemonia masculina levou a uma ênfase na visualidade do conhecimento, e por seguinte, na valoração de uma série de conceitos correlatos, como objetividade, tempo espacializado, análises tipo causa-e-efeito, racionalidade determinística e controle. A área da música teria escapado deste quadro, por isso mesmo representando um perigo à hegemonia masculina, principalmente no timbre, ao mesmo tempo o elemento musical menos passível de controle visual e o menos "determinante" no discurso da música erudita. Neste tipo de música, a hegemonia masculina provoca uma idealização dos sons "puros" e padronizados. Já na música popular, os timbres têm um caráter de "incompletos" e "sujos", o que lhes confere mais subjetividade, mas não possibilita o diálogo entre as identidades masculina e feminina. A maioria da música ocidental, assim, estaria marcada por um processo de hegemonia masculina.

Outro estudo importante é Frith (1988), onde o rock é enfocado amplamente, à luz de seus nexos sócio-culturais. Os desenvolvimentos tecnológicos das gravações, que surgem à medida que a música vai sendo industrializada. "Cada novo avanço - discos stereo nos anos sessenta, a eliminação dos ruídos e do desgaste nos compact discs dos anos oitenta - muda a nossa experiência da música" (p.20). Enquanto as companhias gravadoras de música clássica incitaram seus consumidores à mera busca do som puro do original, na música popular gravação passa a ser uma forma de arte, "uma nova forma de comunicação" (p.22).

Numa obra fundamental para o estudo acadêmico da música popular, Middleton (1990) 
começa analisando as teorias de Adorno para a música popular. 0 tom geral é de crítica feroz ao reducionismo que efetua Adorno: sua preocupação seria de notar o que falta nesta música em relação ao seu modelo ideal que teria em Beethoven seu fulcro. Enfocando as opiniões de Adorno sobre o estilo Tin-Pan-Alley, critica os conceitos de regressão da audição, estandartização e pseudo-individuação, mostrando que o filósofo da Escola de Frankfurt usou uma perspectiva etnocêntrica e "culturocêntrica" (p.44), deixando de lado a importância deste estilo não apenas em termos de composição mas também no sentido da performance. Middleton mostra um Adorno amargo e preconceituoso, ainda que, apesar de criticável, representa um marco obrigatório: "qualquer um que queira discutir a importância em se estudar a música popular tem que absorver Adorno para poder ir além dele" (p.35). A música popular porta um significado que é comunicado de forma intensa a seus consumidores. Frith (1988) mostra como, nas canções populares, há um forte interrelação entre a letra, a música e a condição "sócioemocional" que a canção descreve e representa, num realismo cheio de convenções; o autor sugere que a significação da canção não é organizada exclusivamente pela letra da canção. Menezes Bastos (1996) concorda com Frith, levando adiante a questão e propondo a canção como diálogo entre música e língua (p.18), e mais adiante, como tentativa de tradução da língua "em" música (p.29). Em sua análise de uma canção de Noel Rosa, Menezes Bastos mostra como há, no nível musical, uma evocação que a letra posteriormente colocada parece ter 
desvendado, o que aponta diretamente para a viabilidade de uma semântica da música.

A música erudita é também objeto de estudos com esta mesma perspectiva. É nesta direção que Agawu (1991) dá um grande passo, em seu estudo sobre a língua "falada" por Haydn, Mozart, Beethoven e seus contemporâneos. Delimitando assim seu campo de estudo na música do período clássico, Agawu expõe seu modelo de compreensão da sintaxe, do discurso e da natureza da comunicação desta música analisando três peças exemplares. Sua análise semiótica se vale dos modelos analíticos de Rosen, Ratner e análise schenkeriana num esforço unificador em direção a um método analítico que desvende a "agenda secreta" da música. Propõe a interação entre os níveis da estrutura e a expressão, este último deslindado pela noção de topic. Outro avanço nesta temática é o desvendamento da socialidade da música de Bach, idealizada e sacralizada pela maioria dos músicos eruditos, que é realizado por McClary (1987). Escondidos nos meandros da dita universalidade da música de Bach, McClary nos apresenta um discurso fortemente apegado à identidade nacional, um conflito constante entre os princípios do pietismo e do luteranismo ortodoxo, e também uma preocupação com as normas sociais da época com relação ao comportamento feminino: um novo Bach se nos apresenta, não menos genial, mas mais humano! Bach estudou técnicas de Vivaldi para construirse virtuoso, mantendo-se à margem da glória por uma opção estratégica. As novas abordagens que McClary propõe apontam para novas contribuições à cultura: a desconstrução do cânone, a "visibilidade" da fina síntese de forças ideológicas opostas que há em suas composições 
e a apropriação de Bach para nossos próprios fins políticos.

De todos os estudos aqui mencionados, sejam do campo disciplinar da Etnomusicologia, da Sociologia da Música, da Psicologia da Música ou Semiologia da Música, tendo como objeto tanto a música indígena, popular ou erudita, pode-se traçar em comum a idéia de que a música é algo que porta uma verdade que não se encontra exclusivamente na sua dimensão sonora, não sendo portanto passível de uma definição meramente como a arte de organizar os sons; se assim fosse, um aprofundamento da Musicologia poderia dar conta de reter todo seu significado. O sentido da música aponta, no entanto, para outros domínios da cultura; seu significado opera em vários níveis de consciência. Portanto deve-se tomar como pressuposto básico que a compreensão da música só pode se dar pelo interrelação entre os sons musicais e fenômenos que se dão fora deles, que se originam na sociedade, na cultura ou na mente humana.

\section{Breve Etnografia de uma Performance de Jazz}

Nesta segunda parte deste texto, pretendo relatar uma experiência pessoal de distanciamento e performance, e esboçar uma contribuição à análise semiótica do jazz. Após um ano afastado de performances musicais, imerso num oceano de textos e idéias sobre as culturas e as diferenças, fui convidado para participar como pianista de uma pequena série de apresentações de um quinteto de saxofones de São Paulo por bares de Florianópolis. O 
repertório era basicamente jazz e música instrumental brasileira, a função era acompanhar o grupo juntamente com um baixista e um baterista, constituindo a "cozinha", ou seja, o conjunto de instrumentos que fornece a base rítmico-harmônica da música, o "tapete" sobre o qual os solistas vão deitar e rolar. A grana era curta mas a chance para desenferrujar era boa. Minha expectativa era de tocar e curtir, como nos velhos tempos em que tocava jazz quatro noites por semana para a paulicéia desvairada. Não estava esperando que o efeito dos estudos antropológicos fosse tão "destruidor": desde os primeiros instantes dos dois ensaios que fizemos até nossa despedida, senti um estranhamento em relação não só aos meus ex-colegas de profissão -de suas falas, as visões de mundo saltavam como eu nunca percebera antes-, mas intensamente em relação à própria música, o que para mim foi um susto aterrador. Como espantar-me com aquilo que fiz por tanto tempo, que conheço tão bem? "0 espanto carrega a filosofia e impera em seu interior" (Heiddeger, citado em Cardoso de Oliveira,1988): teria eu virado filósofo? Lembrando da familiaridade deste espanto heiddegeriano com o conceito antropológico de estranhamento, que nada mais é que um espanto diante do outro, ou ainda diante da própria disciplina, como o espanto de Cardoso de Oliveira (1988), veio-me a pergunta: teria eu sido acometido da doença antropológica, do mal esquizóide que nos exila do familiar ao mesmo tempo nos incita a mergulhar nele: o terrível "olhar duplo"? É tomado por uma autoconsolação soropositiva que eu tento agora juntar os cacos de memória da minha experiência sem entrevistas nem diário de campo, mas que 
epistemologicamente foi uma leitura etnográfica, e extrair destas "vastas emoções e pensamentos imperfeitos" (à la Rubem Fonseca) algo que confirme minha idéia de que o jazz é um gênero musical absolutamente convencional e que ele dita algo que concerne a normas socioculturais; enfim, pretendo esboçar aqui um quadro inicial, necessariamente superficial do ponto de vista teórico, mas que me possibilite, num momento posterior, contribuir mais substancialmente para as análises semióticas do jazz .

Estranho no próprio ninho, em busca dos preceitos elementares que eu parecia ter esquecido, fui favorecido pelo fato de que 0 quinteto de saxofonistas era constituído de um mestre e quatro de seus alunos.

Por isso, os ensaios tinham também um caráter pedagógico, como um prolongamento dos ensinamentos anteriores, agora sob a pressão da data marcada. O mestre interrompia uma música diversas vezes para explicar para os alunos como era o jeito certo, como deveria ser para que o grupo tivesse swing. Declaradamente, tratava-se de uma aproximação a uma referência que todos eles tinham na cabeça: os grupos norte-americanos, onde a perfeição do estilo era alcançada. E este estilo é pontual: trata-se de um jazz específico, o chamado Bebop, que tinha seu príncipe em Charlie Parker, que delineou os limites e as convenções que fundam essa linguagem. Decididamente esse jazz (atenção: é especificamente ao Bebop que eu me refiro quando falo de jazz) é uma linguagem, perseguida por milhares de músicos em seus estudos, falada por milhares de músicos no 
mundo todo. Ouvindo as explicações do mestre, pude notar inicialmente dois pontos:

- trata-se de um conhecimento altamente especializado, que pressupõe não apenas dados técnicos, como detalhes de expressividade. 0 tratamento do estilo é como ele fosse uma língua que se deve falar com o público; e a pressão da proximidade da data de apresentação, bem como a consciência de que a audiência reconhece esta língua -estando portanto capaz de reconhecer deslizes, falhas e inadequações- tornaram estes dois ensaios uma perseguição quase devocional ao modelo referencial. Cada detalhe de respiração, de postura, de resultado sonoro era comentado pelo mestre.

- trata-se de um conhecimento sobre algo que não é totalmente englobado pelo discurso verbal, parecendo que este é sempre insuficiente para a questão exata. A maneira de se referir a determinado objetivo é quase metafórico: "swingar" é ser mole, atrasar, "quebrar" o ritmo, a "cozinha" está "atrás", a música ter que ser "para cima", o som ter que ser soprado, de "veludo" nas baladas, a música rápida é para "arrebentar", "quebrar tudo", os improvisos são para "arrasar", o mestre é uma "fera", improvisa como um "monstro", as "quebradas", etc.

O discurso nativo é especializado e cheio destas metáforas que estão literalmente dizendo o que a música pode dizer, dando pistas para pousar a música na cultura. Há uma inefabilidade da música, mas ao mesmo tempo há uma discursividade dos músicos (e da audiência, se consultada) que pode ser objeto 
de uma interpretação, podendo formar uma compilação de expressividades verbais.

Estas expressividades se inscrevem também no nível da estrutural da música e apontam para uma especificidade convencional, segundo creio, irredutível. O que Agawu (1991) constrói com relação à música clássica pode ser reconstituído aqui, já que as associações que aparecem nestes discursos e mesmo na literatura nativa (textos dos jazzistas, métodos, entrevistas publicadas) podem constituir um quadro de unidades gestuais (que Agawu chamou universe of topic) que recomponham o sentido de um elemento musical. E não se trata apenas da formação deste universo de gestos: ele efetivamente pode ser incorporado no corpo da análise musical, fornecendo um roteiro que restitui uma narrativa verbal coerente do Bebop.

Eu poderia estar caminhando neste sentido, mas não me ocorreu levar um gravador para os ensaios; não pensei em tomar a experiência que iria ter como objeto de estudo, eu apenas ia tocar com os caras. Tal despreocupação despiu-me da consciência de que eu estava ali realizando uma etnografia; se por um lado me faltou o gravador e um caderno de anotações, por outro os "imponderáveis da vida real" se sucederam sem impedimentos e eu pude formar um "corpus inscriptorum", ainda que modesto.

Alguns pressupostos são básicos para se ingressar no universo musical do jazz. A começar pela partitura, todo aspirante a jazzista deve saber antecipadamente que a notação musical utilizada, nascida em berço erudito, é inadequada para o jazz; mesmo assim sendo usada, a chave é lê-la de forma "errada", 
tornando doze o que é quatro, três o que é um: pode-se chamar este processo de "compostização", um mecanismo imediato para os leitores de partitura mais experientes. A partitura de jazz, se lida "literalmente", pode parecer uma marcha militar ou uma canção de ninar, tudo menos jazz. A "compostização", no entanto, não pode ser algo mecânico, correndo o risco de não ter swing. Para "swingar", além dela é necessário deslocar os acentos do primeiro e terceiro para o segundo e quarto tempos. 0 jazzista conta 1,2,3,4, mas os tempos considerados fortes, aqueles nos quais ele estala os dedos quando estão livres, são o $2^{\circ}$ e $\circ 4^{\circ}$, contrariando novamente os pressupostos teóricos da música européia. Na dimensão rítmica parece uma guerra entre Europa e África, terminando pela incorporação "criolizada" do modelo europeu: o que alias se deu em inúmeras outras questões.

Mas não basta só entortar o ouvido e ouvir a música pelos tempos 2 e 4, para ter swing tem que ter aquilo que o mestre mencionou como "moleza". Significa que se deve atrasar as frases, como que tentando "ralentar" o ritmo firme da base. Como apesar disso este se mantém, há um complexo equilíbrio entre atrasar e a intenção de atrasar, de modo que por vezes o atraso é nítido, mas ele tem que estar sempre na cabeça do solista. Sim, porque, segundo apregoam os nativos (e eu já verifiquei e repeti isto em tantos outros momentos de minha vida, como ex-nativo que me coloco aqui), a intenção de atraso está somente nos solistas, estruturalmente no aspecto melódico, sendo que o baixo deve seguir o pulso to estritamente como um metrônomo. 0 gesto de moleza parece um traquejo corporal, conferindo uma 
sensualidade esperta que pode ser semelhante ao jeito do malandro brasileiro. As técnicas de walking bass destacam a necessidade de se agarrar ao pulso, mesmo porque o baixo é o único que deve ter a intenção de manter o tempo: a bateria deve "jogar o tempo para frente", estar sempre adiantada. Segundo ouvi de vários mestres (e deste também), e pude ter o prazer de constatar tocando, ou seja, no meio desse fogo cruzado de pulsos, esse é um segredinho que faz o jazz acontecer, principalmente nas peças mais rápidas. Nesta batalha rítmica, o piano leva o papel coadjuvante de pontuador harmônico, como o mestre deixou claro quando me pediu para dar uns "toques na harmona", sendo permitido que nos espaços vazios de saxofone (eles precisam respirar!) o piano se precipitasse num solinho com caráter de comentário, assumindo a tendência "molenga" dos solistas: "neste trecho aqui você pode falar um pouquinho", disse o mestre, uma mão apontando a partitura, a outra teclando o ar.

0 baixo no tempo, a bateria adiantando, os saxofones atrasando, o piano pontuando, todos em busca do swing grupal, pois é necessário, senão a audiência não gosta. O papel da "cozinha" neste objetivo é o de dar um fundo consistente e firme para os solistas. O termo "cozinha" é muitas relacionado à origem negra do samba e do jazz, sendo que seu uso revela, portanto, um preconceito racial, além do desfavoritismo espacial de colocá-la senão atrás, com certeza fora de destaque; mesmo assim, paradoxalmente, os músicos dizem que os jazzistas negros têm swing "no sangue". Há entre os músicos muitas opiniões profundamente marcadas por um determinismo biológico (os 
músicos deveriam estudar um pouco de antropologia!), ao mesmo tempo pela frustração que decorre da impossibilidade de uma transfusão (tornar-se um negro tocando), sendo possível quando muito uma aproximação (imitar um negro tocando). Um estudo destas e outras expressões revelaria, creio eu, um aspecto colonial, algo sobre um caráter imperialistahomogenizador no jazz. Nos Estados Unidos, cozinha é rhythmic section, termo talvez menos ideológico, mas que revela a idéia de que a harmonia e o ritmo se fundem numa mistura básica que fica "atrás" da melodia. Noto que esta dicotomização destaque melódico/fundo rítmico-harmônico é algo sempre presente na música ocidental desde o período do Barroco, onde começa vigorar a duradoura tirania da melodia sobre os aspectos rítmico-timbralharmônicos. Pode-se aumentar a abrangência desta generalização e incluir a noção de núcleo/periferia na música das sociedades indígenas, que Menezes Bastos destaca como uma característica geral da música amazônica (Menezes Bastos,1978). No caso estudado, o núcleo não é apenas a melodia, mas o conjunto de sons que consideramos propriamente musicais (os cantos, os instrumentos), enquanto a periferia é constituída por eventos onomatopéicos, gritos, imitações de animais, etc. (o que estaria atrás, neste caso? a música como base para os solos onomatopéicos? o contrário? N.D.A.?).

Os termos "cama" e "tapete" também servem para se referir à base rítmico-harmônica do jazz para o improviso. Associa-se, assim, a idéia da criação instantânea de melodias com a idéia de deitar em cima, ou de "mandar ver" na frente que a base "segura" atrás. "Deitar e rolar", 
"mandar ver", "quebrar tudo"? Só se for "fera". E um dos pré-requisitos essenciais para ser "fera" , vencer (o tempo?) na selva das harmonias e ser um bom improvisador. 0 jazzista tem sua gramática implícita no famoso Omni Book, livro de transcrições dos grandes solos de Charlie Parker, que funciona como um tratado sem teoria, só com exemplos. Conhecidas as regras para a construção de melodias (o método), é preciso saber como despejá-las incondicionalmente sobre as "camas", tendo o cuidado de violentá-las só um pouquinho (as técnicas). 0 mestre sabe tocar para mostrar que domina a gramática, se quiser, mas ele a toca com elementos transgressores ocasionais, que servem para dar movimento e mais vida. A "fera" conhece essas transgressões, que são absolutamente domesticadas e convencionais, como o uso das outside scales para sair fora (só "um pouquinho") do rigor, mas com muito rigor. Attali (1992) fala da dialética entre ordem e violência na música, a ordem servindo para ela não ser mero ruído indiferenciado, a violência sendo os elementos que desviam da norma da ordem, dando à música movimento e interesse note-se que, para Attali, ordem e violência são construtos ideológicos. É isso que o "fera" sabe fazer: arrasa na gramática e nas convenções para destrui-la, daí o ideal do "quebrar tudo" como gesto de pseudoautodestruição programada do próprio sistema. O solista traidor se afasta da massa amorfa de onde surge, a base rítmico-harmônica, e lança-lhe o veneno mortal que ela já prevê, que é uma brincadeira de destruição que faz parte do negócio. A visão da separação do solista em relação à base inclui essa idéia de "acordo", como mostra Menezes Bastos (1994), lembrando que esse acordo 
remete à concerto, o acordo formal entre concertista e orquestra na música clássica desde o século XVII, metáfora musical da relação entre indivíduo e sociedade.

Manuseando esta metáfora poderosa, a "fera" quer vencer na selva, o indivíduo quer vencer na sociedade. A alternância entre reprodução de clichês é desmontagem correta e fugaz das normas e volta às regras elementares é a receita para o sucesso no improviso. Além disso, é preciso haver um clímax, sempre associado ao virtuosismo de passagens muito rápidas e de notas muito agudas, que deve ser um evento próximo do fim do tempo hábil. Mais importante, é preciso terminar de forma conclusiva, de modo que a audiência possa bater palmas como reconhecimento pela adequação do vôo às normas. Aconteceu comigo a seguinte curiosidade: na última música do show, que por convenção deve ser animada, havia um espaço livre para solos de todos os músicos, grande oportunidade para os "cozinheiros" mostrarem seu valor. Foi combinado que lá pelas tantas, quando se julgava que o improviso estava na reta final, os saxofones não solistas tocariam uma melodia de dezesseis compassos que marcaria o final de cada improviso e o início do seguinte. Assim foi com os cinco saxofones, e chegou minha vez! Os saxofonistas saíram da frente, me deixando aparecer para a audiência por pouco tempo, tendo essa permissão um caráter quase de cortesia civilizada por parte dos colonizadores em relação a seus escravos. Fiz um solo absolutamente convencional, com clímax e tudo, fazendo com que o ponto culminante fosse simultâneo à frase demarcadora dos saxofones, o que me pareceu excelente. Deu tudo certo, julguei-me um 
vencedor na vida, e no entanto... diferentemente de todos os outros solos, não houve sombra de palmas no meu, e o solo do baixista logo começou, neste vazio incômodo, eu ainda perplexo. 0 que acontecera?

Já na segunda apresentação, notei que depois da frase demarcadora, os solistas continuavam o solo por alguns segundos, já num espírito de finalização, quase sempre num movimento descendente. Após todos esses sinais viria ainda o marco final -tirar o instrumento da boca, parar de tocar-, e as palmas infalíveis. Eureka! A audiência estava tão ligada na especificidade deste momento de fronteiras flexíveis que o rigor de terminar o solo junto com a melodia demarcadora, que instituía de forma excessivamente pontual o fim do meu solo e o começo do outro, agiu como um ruído de comunicação. Hipótese verificada experimentalmente: bastou algumas notas após a melodia demarcadora, uma escala descendente até a tônica e um gesto tirando as mãos do teclado que um fulguroso aplauso eclodiu após o meu solo. Cumpri minha parte nas normas, estabeleci comunicação e isto foi reconhecido. Obrigação cumprida. Lembrei que diversos jazzistas já me contaram que quando o espaço livre se abre, sentem uma apreensão: a liberdade do tempo livre para improviso contrasta com a prisão da norma, segundo a qual o solo deve ser eficiente no cumprimento das normas, deve levar a um clímax agudo e veloz, deve terminar claramente e arrancar aplausos, tem obrigações a cumprir. Quando a sociedade dá voz ao indivíduo, os espaços livres parecem opressores, as normas se mostram angustiantes. 0 veredito final da audiência é determinante. 
O caso acima serve também para destacar a importância das finalizações no jazz. Há diversas convenções para se acabar uma música. Enquanto alguns finais trabalham com a surpresa, embora também convencionada, outros são absolutamente previsíveis. 0 final tipo caos total é muito empregado: todos solam nervosamente sobre um acorde final, a bateria fazendo evoluções sem pulsação e dando o golpe de misericórdia nesta fermata espalhafatosa: aqui o final é o momento mais tenso da música, sua consumação é uma agonia. No final tipo acorde retumbante, cada instrumento toca sua nota do acorde fortíssimo, sendo que deve haver uma nota muito aguda, de preferência uma das dissonâncias opcionais para o acorde, ou um trêmulo: ao mestre cabia esta nota, voz de anjo ou de demônio? Ou o grito aterrorizado de Munch? (o conhecedor da teoria semiótica diria que pode parecer um ícone, ruído do mundo apropriado pelo sax; ou também um índice, indicando o fim da música como fumaça indica fogo; talvez finalmente um símbolo, de agonia e morte da música... os músicos e a audiência podem dar pistas). O conhecimento de finais possíveis é uma exigência especialmente nas jam sessions, onde se pode optar coletivamente por um ou outro tipo, opção que vai se construindo nos últimos momentos da música. Este conhecimento se alinha ao conhecimento necessário para executar improvisos bem sucedidos como dados também da prática, conhecimentos performáticos, da esfera da técnica e da produção, da poiesis (Molino, s/d), que tratam da ocupação e desocupação de espaços e da individualidade.

A audiência é competente para o julgamento das mensagens comunicadas pêlos 
músicos de jazz, porque o jazz (atenção novamente: refiro-me sempre ao Bebop) é um gênero normativo, com limitações formais claras e absolutamente convencional, e por isso é possível que um código comunicativo seja compartilhado com a audiência. Mas isto não se restringe ao jazz: Mozart já sabia disso ao colocar uma música alla turca numa passagem de uma ópera, sabendo que a audiência receberia isso como uma injeção de comédia (Agawu, 1991). O jazz dita algo que se experimenta concreta e intimamente, algo que nos fala da base fundante da sociedade ocidental, especialmente norte-americana, do individualismo, da busca de acordo com a sociedade. O Bebop é uma língua, um estilo homogêneo cheio de referências extra- musicais que se encaminham numa espécie superfície textualmente fragmentada (o nível da "semiosis extroversiva", conforme Agawu) e que são ouvidas e reconhecidas pelos músicos e pela audiência. Não são princípios abstratosmetafísicos que fundam um estilo como esse: a base é humana e socialmente alterável, diferentemente do que supõem os que se filiam à posição "neo-pitagórica" (McClary, 1987). Seguindo as trilhas que Agawu abriu para a análise da música clássica e McClary para a música barroca, pode-se chegar ao que nos dita o jazz.

\section{Conclusão}

$\mathrm{Na}$ primeira parte deste texto foram apresentados alguns estudos musicais de tendências variadas, com ênfase nos pilares teóricos da Etnomusicologia. $\mathrm{Na}$ segunda, há uma reflexão sobre uma experiência etnográfica 
e performática em um gênero musical chamado jazz, tendo o estilo bebop como "subparole" (Agawu,1991), com o objetivo de afirmar que é possível encontrar traços de sentido da música ocultados em expressões verbais dos músicos e nas regras que constróem as convenções. E esta viabilidade tange a música popular em geral, herdeira dos fundamentos harmônicosestruturais da música Européia dos séculos XVIIXIX, segundo universal musical do Ocidente (Menezes Bastos,1994). Ambas as partes deste trabalhos se unem juntamente na pretensão de compreender a totalidade sócio-cultural da música, onde se imbricam as dicotomias som/sentido e som/cultura. O sentido e a cultura, exilados da música pela saliência de seu aspecto sônico, são objetos de um projeto de entendimento integral da música, que se guiam tanto pelas luzes semióticas de Agawu e McClary quanto pelo desvendamento das teorias musicais "exóticas" através da investigação científica. Os estudos da Etnomusicologia têm revelado que os sistemas musicais são basicamente comunicativos, invadindo todas as dimensões culturais. O papel da música nas sociedades humanas é central, havendo a necessidade de dialogar com outros domínios, das artes, discurso, cosmologia, religião, filosofia e política, para se dar conta da compreensão desta significação estratégica da música. Um estudo antropológico aprofundado da música, que toque no seu fundo sócio-cultural, no seu nível semântico, ao mesmo tempo envolve necessariamente uma minuciosa análise de seu nível expressivo. A tradição musicológica, esquecendo-se da plenitude representacional da música, deixou de lado a conjunção destes níveis. Neste sentido, a Etnomusicologia 
recompõe esta plenitude e se torna uma Musicologia "com homem", ou uma Antropologia "com música".

\section{Referências bibliográficas}

ABRAHAM, Otto e HORNBOSTEL, Erich M. Von, "Zur Psychologie der Tondistanz", Zeitschrift für

Psychologie, 1925, 98:233-249.

AGAWU, V.Kofi, Playing with Signs: a Semiotic Interpretation of Classic Music. Princeton:

Princeton University Press, 1991.

ATTALI, Jacques, Noise: The Political Economy of Music. Minneapolis: University of Minnesota Press, 1992.

BASSO, Ellen B, A Musical View of the Universe: Kalapalo Myth and Ritual Performances, Philadelphia, University of

Pennsylvania Press,1985.

BERLINER, Paul, Thinking in Jazz: The Infinite Art of Improvisation, Chicago: University of Chicago Press, 1994.

BLACKING, John, How musical is man? Seattle: University of Washington Press,1973.

CARDOSO DE OLIVEIRA, Roberto, Sobre Pensamento Antropológico, Rio de Janeiro: Tempo Brasileiro,1988.

CHRISTENSEN, Dieter, Erich M. Von Hornbostel, Carl Stumpf and the Institutionalization of Comparative Musicology, In: Comparative Musicology and Anthropology of Music, 1991.

FELD, Steven, Sound and Sentiment: Birds, Weeping, Poetics and Song in Kaluli Expression, 
Philadelphia: University of Pennsylvania Press, 1982.

, Sound Structure as Social Structure,

Ethnomusicology, Sept.1984, pp.383-409.

FRITH, Simon, Music for Pleasure. New York:

Routledge, 1988.

HILL, Jonathan, Keepers of the sacred chants:

the poetics of ritual power in na Amazonian

society. Tucson: University of Arizona

Press, 1983.

KEIL, Charles, Tiv Song: The sociology of Art in a classless society, Chicago: Chicago University Press, 1979.

MCCLARY, Susan, The blasphemy of talking politics during Bach Year. In: Music and Society:

The politics of composition, performance and reception. Cambridge: Cambridge University Press, 1987.

MENEZES BASTOS, Rafael José de, A Musicológica Kamayurá: Para uma antropologia da comunicação no Alto-Xingu.

Brasília:Fundação Nacional do Indio,1978.

, A Festa da Jaguatirica: Uma Partitura

Crítico-Interpretativa. Dissertação de doutorado

em antropologia, USP,1990.

, Esboço de uma Teoria da Música: Para

Além de uma Antropologia sem Música e de uma Musicologia sem Homem,

Anuário Antropológico 95, 1994.

A Origem do samba como Invenção no

Brasil: Sobre o "Feitio de Oração" de Vadico e Noel Rosa, Revista Brasileira de Ciências

Sociais, n. 31, ano XXI, pp.156-177,1996. 
MENEZES BASTOS, Rafael J. de, e LAGROU, Elsje, Arte, Cosmologia e Filosofia nas Terras Baixas da América do Sul, Projeto Integrado de Pesquisa, UFSC, 1995.

MERRIAM, Alan P., The Anthropology of Music. Northwestern University Press, 1964.

, Definitions of "Comparative Musicology" and "Ethnomusicology": a Historical-theoretical perspective, Ethnomusicology 21(2),1977, pp.189-204.

MIDDLETON, Richard, Studying Popular Music, Philadelphia: Open University Press, 1990.

MONSON, Ingrid, Saying Something: Interaction and Improvisation in Jazz, Chicago: University of Chicago Press,1997.

NETTL, Bruno, Theory and Method in Ethnomusicology. London: Free Press,1964.

PIEDADE, Acácio Tadeu, Música Ye'pâ-masa: Por uma Antropologia da Música no Alto Rio Negro, tese de mestrado em Antropologia Social, UFSC, 1997a.

, Música Instrumental Brasileira e Fricção de Musicalidades, Antropologia em Primeira Mão, 21, PPGAS/UFSC, 1997b.

RAFFMAN, Diana, Language, Music and Mind. London, The MIT Press, 1993.

ROSEMAN, Marina, Temiar Healing Sonds from the Malasyan Rainforest: Temiar music and Medicine. Berkeley: University of California Press, 1991.

SEEGER, Anthony, Why Suyá sing: a Musical Anthropology of an Amazonian People.

Cambridge: Cambridge University Press, 1987. 
SCHNEIDER, Albrecht, Psychological Theory and Comparative Musicology, In: Comparative Musicology and Anthropology of Music, 1991.

SHEPHERD, John, Music and male hegemony, In: Music and Society: The politics of composition, performance and reception. Cambridge:

Cambridge University Press, 1987.

Press, 1991. , Music as Social Text, Cambridge: Polity

STUMPF, Carl, Tonpsychologie, 2 vols., Leipzig:Hirzel, 1883. 